\title{
Food concern and its associations with obesity and diabetes among lower-income New Yorkers
}

\author{
Sirin Yaemsiri ${ }^{1}$, E Carolyn Olson ${ }^{2, *}, \mathrm{Ka} \mathrm{He}^{1,3}$ and Bonnie D Kerker ${ }^{2}$ \\ 'Department of Epidemiology, UNC Gillings School of Global Public Health, University of North Carolina, \\ Chapel Hill, NC, USA: ${ }^{2}$ Bureau of Epidemiology Services, NYC Department of Health and Mental Hygiene, \\ Gotham Center CN\#6, 42-09 28th Street, 7th floor, Queens, NY 11101 , USA: ${ }^{3}$ Department of Nutrition, \\ UNC Gillings School of Global Public Health and School of Medicine, University of North Carolina, \\ Chapel Hill, NC, USA
}

Submitted 17 November 2010: Accepted 6 June 2011: First published online 3 August 2011

\begin{abstract}
Objective: To examine food concern (FC) and its associations with obesity and diabetes in a racially diverse, urban population.

Design: Cross-sectional population-based survey.

Setting: Five boroughs of New York City.

Subjects: Lower-income adults ( $n$ 5981) in the 2004 New York City Community Health Survey.

Results: The overall prevalence of obesity was $24 \%$ and was higher among FC than non-FC white men and women, black women, US- and foreign-born whites and foreign-born blacks. In multivariable analysis, FC was marginally associated with obesity $(\mathrm{OR}=1 \cdot 18,95 \% \mathrm{CI} 0 \cdot 98,1 \cdot 42)$ among all lower-income New Yorkers, after controlling for socio-economic factors. The association of FC and obesity varied by race/ethnicity, with FC being positively associated with obesity only among white New Yorkers. FC whites had $80 \%$ higher odds of obesity than whites without FC $(\mathrm{OR}=1 \cdot 80 ; 95 \%$ CI $1 \cdot 21,2 \cdot 68)$, with a model-adjusted obesity prevalence of $20 \%$ among non-FC whites $v$. $31 \%$ among FC whites. FC was not associated with diabetes after controlling for obesity and socio-economic factors. Conclusions: The prevalence of obesity was significantly higher among FC whites and certain subgroups of blacks. FC was positively associated with obesity risk among lower-income white New Yorkers. Programmes designed to alleviate FC and poverty should promote the purchase and consumption of nutritious, lowerenergy foods to help address the burden of obesity in lower-income urban populations.
\end{abstract}

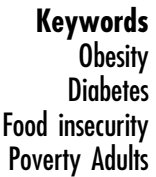

Obesity

Diabetes Poverty Adults
Obesity and diabetes are rapidly growing epidemics in New York City (NYC). The prevalence of obesity in NYC increased from $19 \cdot 5 \%$ in 2002 to $22 \cdot 8 \%$ in $2007^{(1,2)}$. Likewise, the prevalence of diabetes increased from $8 \cdot 1 \%$ in 2002 to $9 \cdot 1 \%$ in $2007^{(1,2)}$. Both obesity and diabetes are associated with poverty and low socio-economic status globally ${ }^{(3)}$, nationally ${ }^{(4)}$ and locally in $\mathrm{NYC}^{(5,6)}$.

The behavioural economic theory of food insecurity pertaining to food purchasing and consumption patterns attempts to explain the positive associations between poverty and obesity and diabetes. Food insecurity exists 'whenever the availability of nutritionally adequate and safe foods or the ability to acquire acceptable foods in socially acceptable ways is limited or uncertain, ${ }^{,(7)}$. Individuals who are food insecure may tend to buy and consume low-cost but energy-dense foods, resulting in a poor diet that leads to obesity over time ${ }^{(8)}$.
Accumulated evidence suggests that a positive association between food insecurity and obesity exists in women, but has not been consistently found in $\operatorname{men}^{(9)}$, making sex a likely modifier of the relationship between food insecurity and obesity. In addition, the few studies that have examined the impact of race/ethnicity on this relationship suggest that the association may be stronger in minorities ${ }^{(10-12)}$. Place of birth and race/ethnicity are markers of both acculturation and diet. When an individual's finances become limited, these two factors may affect an individual's food choices, which play a role in the development of obesity. Since cultural differences play a role in food choices, we hypothesized that place of birth, in addition to race/ethnicity, could also be related to differences in the food insecurity and obesity association.

Poor diet has been implicated in the incidence of diabetes as well ${ }^{(13)}$. While obesity is the most prevalent cause 
of diabetes, other mechanisms, such as public assistance, may link food insecurity with diabetes independent of obesity. Lower-income individuals who experience food insecurity may receive monthly lump sums of public assistance. The cycle of assistance may lead to bingeing at the beginning of the month when individuals have the means to purchase food and fasting when resources are depleted $^{(14,15)}$. This feast-famine cycle has been associated with a biological predisposition to diabetes in animal models ${ }^{(16)}$. Two studies have reported conflicting results on the association between food insecurity and diabetes, one finding no association ${ }^{(17)}$ and one finding a positive association independent of weight status ${ }^{(18)}$.

In the present study, we used a city-wide representative sample of lower-income adult New Yorkers to examine concern about food, as a proxy for food insecurity, and its associations with obesity and diabetes in a large, diverse urban environment. We further explored differences in the food concern (FC) and obesity association by sex, race/ethnicity and place of birth.

\section{Experimental methods}

\section{Study population}

We conducted a cross-sectional analysis of the 2004 NYC Community Health Survey (CHS), a population-based survey of 9585 non-institutionalized adults aged 18 years or older conducted by the NYC Department of Health and Mental Hygiene. Adults living in a household with a landline telephone in NYC's five boroughs were eligible to participate after giving oral consent. The CHS study protocol was approved by the NYC Department of Health and Mental Hygiene Institutional Review Board.

\section{Sampling frame}

The CHS used a stratified random sample design to provide city-wide and neighbourhood-level estimates of health outcomes and health-related behaviours. Probability of selection was based on neighbourhood of residence, defined by thirty-four zip-code aggregations, and the number of adults in the household. The household was selected using random-digit-dialling methods, and one adult was randomly selected as the respondent in each eligible household. The survey was conducted using a computer-assisted telephone interviewing system in more than forty languages with a translation service if necessary. The 2004 CHS had a cooperation rate of $59 \%$ (proportion of all cases interviewed of all eligible units contacted) ${ }^{(19)}$. The post-stratification weights adjusted all final results to represent the entire population of New Yorkers.

\section{Study sample}

To examine the health effects of FC stemming from possible lack of financial resources among New Yorkers with low and lower-middle income (referred to as 'lower-income'), we included only CHS participants whose household income was less than $400 \%$ of the federal poverty level (FPL; $n$ 5145) or who did not know their household income ( $n$ 836), resulting in a total sample size of 5981. For a household of four individuals living in the continental USA, the FPL in 2004 was $\$$ US $18850^{(20)}$. The $400 \%$ of the FPL cut-off for the population of interest in our study should encompass the broadest spectrum of poverty in NYC, where the cost of living is substantially higher than in other US cities. According to the weighted 2004 CHS, $10 \cdot 1 \%$ of all adult New Yorkers did not know their household income. Individuals who did not know their household income level were similar to lower-income New Yorkers for the key socio-economic indicators of race/ ethnicity and education, as well as in the proportion born in the USA and living with children. Individuals who did not know their household income were included to increase sample size after a sensitivity analysis found that their inclusion did not alter any results.

\section{Food concern}

FC status was assessed among lower-income adult New Yorkers using the assessment question from the Social Context Module of the Behavioral Risk Factor Surveillance System, a national cross-sectional telephone survey ${ }^{(21)}$. Participants answered the yes/no question: 'In the last 30 days, have you been concerned about having enough food for you or your family?' This question has been previously used for studying the FC and obesity association in Louisiana, New York State and Washington State ${ }^{(22,23)}$.

\section{Obesity and diabetes}

BMI was calculated by dividing self-reported weight in kilograms by the square of self-reported height in metres. Participants who refused to report their height or weight were asked follow-up questions to determine their BMI category. Since FC prevalence was similar among underor normal weight (BMI $<25 \mathrm{~kg} / \mathrm{m}^{2}$ ) and overweight (BMI 25 to $<30 \mathrm{~kg} / \mathrm{m}^{2}$ ) respondents, we created a dichotomous variable to classify respondents with $\mathrm{BMI} \geq 30 \mathrm{~kg} / \mathrm{m}^{2}$ as obese $v$. those with $\mathrm{BMI}<30 \mathrm{~kg} / \mathrm{m}^{2(24)}$. Diabetes was assessed using the question: 'Have you ever been told by a doctor that you have diabetes?' Women who reported having gestational diabetes were not classified as having diabetes.

\section{Statistical analysis}

We examined the demographics of lower-income New Yorkers, as well as the prevalence of FC, obesity and diabetes in this population, age-adjusted to the 2000 US Standard Population. Next, we estimated the unadjusted prevalence of FC by health status and socio-economic characteristics. We conducted stratified analyses to examine the prevalence of obesity, an indicator of public health burden, by FC status and sex, race/ethnicity and place of birth. Student's $t$ tests were used to assess 
differences (two-sided $P \leq 0 \cdot 05$ ) in prevalence between subgroups for all bivariate analyses.

The associations between FC and obesity and between FC and diabetes in lower-income New Yorkers were examined using two multivariable logistic regression models. A number of lifestyle and socio-economic characteristics were considered as potential confounders based on existing literature ${ }^{(9)}$ : sex (male, female), age (18-24, 25-44, 45-64, 65 years and older), race/ethnicity (white, black, Hispanic, Asian/Pacific Islander, other), place of birth (US born, foreign born), education level (less than high school, high-school graduate, some college or technical school, college graduate), household income (as a percentage of the FPL; $<100 \%, 100 \%$ to $<200 \%, 200 \%$ to $<400 \%$, don't know), number of children (none, one or more), general health (excellent/very good, good, fair, poor) and obesity status (yes, no; only added to diabetes model). We examined possible differences in the association between FC and obesity by sex, race/ethnicity and place of birth by adding interaction terms to the multivariable model one at a time, testing for significance at the $P \leq 0 \cdot 10$ level. We excluded individuals with missing or 'other' sex, race/ethnicity or place of birth information from the stratified analysis. We examined the association between FC and diabetes while controlling for the potential confounders listed above and then with additional adjustment for obesity status, to determine if the hypothesized association was mediated through obesity status.

All analyses were weighted to account for probability of selection (number of adults in each household and number of residential telephone lines) and neighbourhood composition (age, race/ethnicity, sex) according to the 2000 US Census ${ }^{(25)}$, weighting the sample up to the NYC population. Analyses were conducted using the statistical software package SAS-callable SUDAAN version 10.0 (SAS Institute, Cary, NC and RTI International, Research Triangle Park, NC, USA) to account for sampling methodology.

\section{Results}

FC was assessed among lower-income New Yorkers, who make up $64.3 \%$ of all adult New Yorkers. Table 1 shows the characteristics of lower-income New Yorkers. More than half $(56 \cdot 7 \%)$ were female and approximately half $(50.9 \%)$ were born outside the USA. Non-Hispanic whites constituted $25 \cdot 8 \%$ of lower-income New Yorkers; non-Hispanic blacks, 25.6\%; Hispanics, 33.3\%; Asians or Pacific Islanders, $11.4 \%$; and others, $3.9 \%$. Nearly one in three $(30.5 \%)$ lived below $100 \%$ of the federal poverty limit. Approximately one in four $(26 \cdot 4 \%)$ lowerincome adult New Yorkers reported FC, one in four (23.5\%) were obese based on self-reported height and weight, and one in ten $(10 \cdot 2 \%)$ reported having diabetes. Among lower-income adults, $49 \cdot 1 \%$ reported living with at least one child.
Table 1 Characteristics of lower-income New Yorkers, 2004†

\begin{tabular}{|c|c|c|c|}
\hline \multirow[b]{2}{*}{ Characteristic } & \multirow[b]{2}{*}{$n$} & \multicolumn{2}{|c|}{ Weighted prevalence } \\
\hline & & $\%$ & $95 \% \mathrm{Cl}$ \\
\hline \multicolumn{4}{|l|}{ Reported food concern } \\
\hline No & 4417 & $73 \cdot 6$ & $72 \cdot 1,75 \cdot 0$ \\
\hline Yes & 1530 & $26 \cdot 4$ & $25 \cdot 0,27 \cdot 9$ \\
\hline \multicolumn{4}{|l|}{ BMI category $\left(\mathrm{kg} / \mathrm{m}^{2}\right)$} \\
\hline Under/normal weight $(<25)$ & 2334 & $42 \cdot 6$ & $40 \cdot 9,44 \cdot 2$ \\
\hline Overweight $(25$ to $<30)$ & 1924 & $34 \cdot 0$ & $32 \cdot 4,35 \cdot 6$ \\
\hline Obese $(\geq 30)$ & 1462 & 23.5 & $22 \cdot 2,24 \cdot 8$ \\
\hline \multicolumn{4}{|l|}{ Reported having diabetes } \\
\hline No & 5247 & $89 \cdot 8$ & $88 \cdot 9,90 \cdot 6$ \\
\hline Yes & 712 & $10 \cdot 2$ & $9 \cdot 4,11 \cdot 1$ \\
\hline \multicolumn{4}{|l|}{ Sex } \\
\hline Male & 2135 & $43 \cdot 3$ & $41 \cdot 7,44 \cdot 9$ \\
\hline Female & 3846 & $56 \cdot 7$ & $55 \cdot 1,58 \cdot 3$ \\
\hline \multicolumn{4}{|l|}{ Age group (years) } \\
\hline $18-24$ & 669 & $16 \cdot 7$ & $15 \cdot 3,18 \cdot 1$ \\
\hline $25-44$ & 2357 & $40 \cdot 6$ & $39 \cdot 1,42 \cdot 2$ \\
\hline $45-64$ & 1679 & $25 \cdot 1$ & $23 \cdot 8,26 \cdot 5$ \\
\hline $65+$ & 1271 & $17 \cdot 5$ & $16 \cdot 5,18 \cdot 7$ \\
\hline \multicolumn{4}{|l|}{ Race/ethnicity } \\
\hline White, non-Hispanic & 1656 & $25 \cdot 8$ & $24 \cdot 6,27 \cdot 1$ \\
\hline Black, non-Hispanic & 1577 & $25 \cdot 6$ & $24 \cdot 3,26 \cdot 9$ \\
\hline Hispanic & 2043 & $33 \cdot 3$ & $31 \cdot 9,34 \cdot 8$ \\
\hline Asian or Pacific Islander & 515 & $11 \cdot 4$ & $10 \cdot 4,12 \cdot 5$ \\
\hline Other & 190 & 3.9 & $3 \cdot 2,4 \cdot 6$ \\
\hline \multicolumn{4}{|l|}{ Place of birth } \\
\hline US born & 3211 & $49 \cdot 1$ & $47 \cdot 5,50 \cdot 7$ \\
\hline Foreign born & 2770 & $50 \cdot 9$ & $49 \cdot 3,52 \cdot 5$ \\
\hline \multicolumn{4}{|l|}{ Education } \\
\hline$<$ High school & 1452 & 23.9 & $22 \cdot 6,25 \cdot 3$ \\
\hline High-school graduate & 1876 & $32 \cdot 6$ & $31 \cdot 2,34 \cdot 2$ \\
\hline Some college/technical school & 1344 & $22 \cdot 3$ & $21 \cdot 0,23 \cdot 7$ \\
\hline College graduate & 1279 & $21 \cdot 1$ & $19 \cdot 9,22 \cdot 4$ \\
\hline \multicolumn{4}{|l|}{ Household income ( $\%$ of FPL) } \\
\hline$<100 \%$ & 1801 & $30 \cdot 5$ & $29 \cdot 1,32 \cdot 0$ \\
\hline $100 \%$ to $<200 \%$ & 1797 & $30 \cdot 0$ & $28 \cdot 5,31 \cdot 5$ \\
\hline $200 \%$ to $<400 \%$ & 1547 & $24 \cdot 7$ & $23 \cdot 4,26 \cdot 0$ \\
\hline Don't know & 836 & $14 \cdot 8$ & $13 \cdot 7,16 \cdot 0$ \\
\hline \multicolumn{4}{|l|}{ Number of children } \\
\hline None & 3229 & $50 \cdot 9$ & $49 \cdot 3,52 \cdot 5$ \\
\hline One & 1120 & $20 \cdot 7$ & $19 \cdot 4,22 \cdot 1$ \\
\hline Two & 935 & $16 \cdot 9$ & $15 \cdot 7,18 \cdot 2$ \\
\hline Three or more & 693 & $11 \cdot 4$ & $10 \cdot 5,12 \cdot 5$ \\
\hline \multicolumn{4}{|l|}{ General health } \\
\hline Excellent/very good & 2064 & $35 \cdot 8$ & $34 \cdot 3,37 \cdot 3$ \\
\hline Good & 2073 & $36 \cdot 2$ & $34 \cdot 6,37 \cdot 8$ \\
\hline Fair & 1339 & $21 \cdot 3$ & $20 \cdot 0,22 \cdot 6$ \\
\hline Poor & 476 & $6 \cdot 8$ & $6 \cdot 1,7 \cdot 6$ \\
\hline
\end{tabular}

FPL, federal poverty level.

tData source: 2004 New York City Community Health Survey. Lower-income $\mathrm{New}$ Yorkers were defined as respondents whose household income was less than $400 \%$ of the FPL or who did not know their household income (total $n$ 5981).

¥Prevalence estimates were weighted to the New York City adult (aged 18 years or older) population according to the 2000 US Census. Food concern, BMI and diabetes estimates were age-adjusted to the 2000 US Standard Population.

\section{Food concern}

Table 2 shows the prevalence of FC by socio-economic and health characteristics. Among lower-income New Yorkers, there was a higher prevalence of FC among obese individuals $(31.5 \%)$ than non-obese individuals (24.8\%). In addition, there was considerable variation in the prevalence of FC by age group, place of birth, education, household income (as a percentage of the FPL), number of children and general health. Individuals in middle age groups were 
Table 2 Prevalence of food concern by characteristics of lowerincome New Yorkers, 2004†

\begin{tabular}{lcc}
\hline & \multicolumn{2}{c}{ Weighted prevalence of food } \\
concern
\end{tabular}

ref., referent category; FPL, federal poverty level.

*Estimate is significantly different from that of the reference group: $P \leq 0.05$. tData source: 2004 New York City Community Health Survey. Lowerincome New Yorkers were defined as respondents whose household income was less than $400 \%$ of the FPL or who did not know their household income (total $n$ 5981).

łPrevalence estimates were weighted to the New York City adult (aged 18 years or older) population according to the 2000 US Census.

more likely to have FC than younger or older age groups. Blacks, Hispanics and Asians were more likely to have FC than non-Hispanic whites, as were those who were born outside the USA compared with those born in the USA. However, prevalence of reported FC did not differ substantially by sex or diabetes status.

\section{Food concern and obesity}

Figure 1 presents stratified analysis of obesity prevalence by FC status, race/ethnicity and sex (Fig. 1(a)) and by FC status, race/ethnicity and place of birth (Fig. 1(b)). Even though their prevalence of FC was the lowest of the racial/ethnic groups, whites who were FC were more likely to be obese than those without FC regardless of sex or place of birth. Among blacks, significant differences in obesity prevalence were found in FC $v$. non-FC women and in those born outside the USA $v$. US-born blacks. No significant differences in obesity prevalences were detected among Hispanics or Asians.

Table 3 presents multivariable logistic regression models of obesity. Adults who were FC had 18\% higher odds of obesity than their non-FC counterparts, although this association did not reach statistical significance (adjusted OR $=1 \cdot 18,95 \%$ CI $0 \cdot 98,1 \cdot 42$ ). There were no significant differences in the association between FC and obesity by sex or place of birth when these interaction terms were added to separate models ( $P$ values for interaction terms $=0 \cdot 28$ and $0 \cdot 62$, respectively). However, the association between FC and obesity did appear to vary by race/ethnicity $(P$ value for interaction term $=$ $0 \cdot 08)$. We found that FC whites had $80 \%$ higher odds of obesity than whites without FC (OR $=1 \cdot 80,95 \%$ CI $1 \cdot 21$, $2 \cdot 68$ ). The model-adjusted obesity prevalence was $20 \%$ among non-FC whites compared with $31 \%$ among FC whites. The odds of obesity did not vary by FC status among blacks, Hispanics or Asians. However, compared with non-FC whites, blacks and Hispanics had higher odds and Asians had lower odds of obesity, regardless of their FC status. These findings remained consistent when examined only among individuals with household incomes <200\% of the FPL.

\section{Food concern and diabetes}

We stratified the prevalence of diabetes by FC status, race, and sex and place of birth. However, we found no evidence of a higher prevalence of diabetes among the FC in any of the subgroups. Table 4 shows the multivariable logistic regression model for diabetes. In the unadjusted model, a modest, non-significant association was observed between $\mathrm{FC}$ and diabetes $(\mathrm{OR}=1 \cdot 18,95 \% \mathrm{CI} 0 \cdot 95,1 \cdot 46$, $P=0 \cdot 13)$. This association disappeared after controlling for socio-economic and health characteristics (adjusted OR = $1 \cdot 06,95 \%$ CI $0 \cdot 83,1 \cdot 35, P=0 \cdot 63)$ and remained unchanged after additionally adjusting for obesity status $(P=0 \cdot 62)$. The model-adjusted diabetes prevalence estimates did not vary substantially by FC status.

\section{Discussion}

In this large, racially diverse population of lower-income adult New Yorkers, the prevalence of obesity was significantly higher among food-concerned (FC) $v$. non-FC white men and women, US- and foreign-born whites, black women and foreign-born blacks. After adjusting for age, sex and other socio-economic characteristics, there was a 
(a)

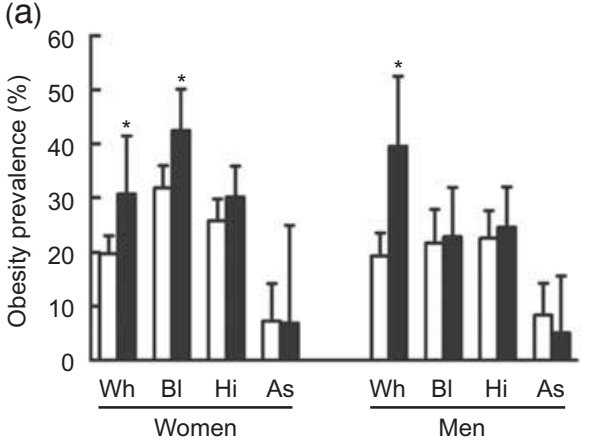

(b)

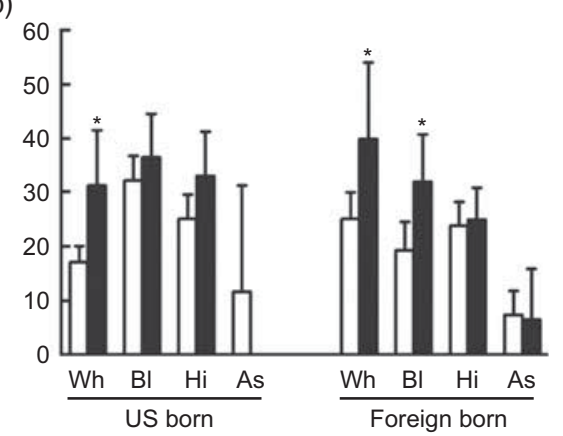

Fig. 1 Comparison of obesity prevalence estimates among those without food concern ( $\square$ ) with those with food concern ( $\square$ ) by race/ethnicity $(\mathrm{Wh}=$ white, $\mathrm{BI}=$ black, $\mathrm{Hi}=$ Hispanic, $\mathrm{As}=\mathrm{Asian})$ and sex (a) and place of birth (b) among lower-income New Yorkers, 2004. Data source: 2004 New York City Community Health Survey. Lower-income New Yorkers were defined as respondents whose household income was less than $400 \%$ of the federal poverty level or who did not know their household income (total $n$ 5981). Results were weighted to the New York City adult (aged 18 years or older) population according to the US Census 2000. Values are means with their $95 \%$ confidence intervals represented by vertical bars. Mean values were significantly different from those of the group without food concern: ${ }^{*} P \leq 0.05$

Table 3 Multivariable odds ratios and prevalence estimates for obesity, lower-income New Yorkers, 2004†

\begin{tabular}{|c|c|c|c|}
\hline & OR for obesity & $95 \% \mathrm{Cl}$ & Obesity prevalence $(\%)$ \\
\hline \multicolumn{4}{|l|}{ Main effects model§ } \\
\hline No food concern & 1.00 & Ref. & 23 \\
\hline Food concern & $1 \cdot 18$ & $0.98,1.42$ & 26 \\
\hline \multicolumn{4}{|l|}{ Interaction model|I } \\
\hline Whites, no food concern & $1 \cdot 00$ & Ref. & 20 \\
\hline Whites, food concern & $1 \cdot 80$ & $1 \cdot 21,2 \cdot 68$ & 31 \\
\hline Blacks, no food concern & 1.63 & $1 \cdot 29,2 \cdot 06$ & 29 \\
\hline Blacks, food concern & $2 \cdot 03$ & $1 \cdot 48,2 \cdot 78$ & 33 \\
\hline Hispanics, no food concern & $1 \cdot 28$ & $1 \cdot 00,1 \cdot 64$ & 24 \\
\hline Hispanics, food concern & $1 \cdot 28$ & $0.95,1.75$ & 25 \\
\hline Asians, no food concern & $0 \cdot 36$ & $0.22,0.61$ & 9 \\
\hline Asians, food concern & 0.25 & $0.09,0.68$ & 6 \\
\hline
\end{tabular}

Ref., referent category.

tData source: 2004 New York City Community Health Survey. Lower-income New Yorkers were defined as respondents whose household income was less than $400 \%$ of the federal poverty level or who did not know their household income (total $n 5981$ ). $\ddagger$ Adjusted obesity prevalences estimated from the multivariable model.

§Odds ratios and prevalence estimates for obesity were adjusted for age, sex, race/ethnicity, place of birth, household income, education, number of children and general health, and weighted to the New York City adult (aged 18 years or older) population according to the 2000 US Census.

\|Model adjusted for covariates in main effects model plus food concern $\times$ race/ethnicity interaction term. This analysis excludes adults reporting a race/ethnicity of 'other'.

marginally positive association between FC and obesity in the general population of lower-income NYC adults. FC whites were significantly more likely to be obese after controlling for other factors. We found no evidence of a positive association between FC and diabetes before or after adjusting for socio-economic factors and obesity status.

Our multivariable finding of a weak association between FC and obesity in the general lower-income NYC population mirrors previous population-based research using the same FC assessment question. Laraia et al. reported that concern about having enough food was significantly associated with morbid obesity among New York State and Louisiana adults in bivariate analysis, but the association was no longer statistically significant after controlling for socio-economic characteristics ${ }^{(22)}$. In Washington state, VanEenwyk found a modest, but statistically significant association between FC and obesity, controlling for race, age group, physical activity, fruit and vegetable intake, income and education ${ }^{(23)}$. It is possible that a self-reported, single-question measurement of FC as used in these studies and ours is not sensitive enough to isolate a clear positive association with obesity ${ }^{(12)}$. Even so, investigators of low-income census tracts in Massachusetts used the eighteen-item US Department of Agriculture Household Food Insecurity Module to measure food insecurity severity, but did not find food insecurity to be associated with self-reported BMI after controlling for socio-economic factors ${ }^{(26)}$. Our sample size may not have been large enough to detect the higherorder interactions suggested by our stratified analyses that would provide a more nuanced understanding of risk by sex, race/ethnicity and place of birth.

The observed differences in NYC's obesity prevalence between those with and without FC were primarily driven 
Table 4 Multivariable odds ratios and prevalence estimates for diabetes, lower-income New Yorkers, 2004†

\begin{tabular}{lccc}
\hline & OR for diabetes & $95 \% \mathrm{Cl}$ & Diabetes prevalence $(\%)$ \\
\hline Model 1: Unadjusted & & & \\
$\quad$ No food concern & 1.00 & Ref. & 11 \\
$\quad \begin{array}{l}\text { Food concern } \\
\text { Model 2: Adjusted\$ }\end{array}$ & 1.18 & $0.95,1.46$ & 10 \\
$\quad$ No food concern & 1.00 & Ref. & 11 \\
$\quad$ Food concern & 1.06 & $0.83,1.35$ & 10 \\
Model 3: Adjusted\| & & Ref. & 11 \\
No food concern & 1.00 & $0.83,1.37$ & 10 \\
Food concern & 1.07 & & \\
\hline
\end{tabular}

Ref., referent category.

tData source: 2004 New York City Community Health Survey. Lower-income New Yorkers were defined as respondents whose household income was less than $400 \%$ of the federal poverty level or who did not know their household income (total $n 5981$ ). $\ddagger$ Adjusted obesity prevalences estimated from the multivariable model.

\$Model 2: Adjusted for age, sex, race/ethnicity, place of birth, household income, education, number of children and general health, and weighted to the New York City adult (aged 18 years or older) population according to the 2000 US Census.

IModel 3: Adjusted for Model 2 covariates and BMI status.

by race/ethnicity and differed from those found in previous studies that used more complex measurement of food insecurity. Adams et al. reported that, regardless of race/ethnicity, the prevalence of obesity was higher among Californian women who experienced food insecurity without hunger than their peers who were food secure. Food insecurity with hunger, however, had a greater impact on obesity risk among blacks, Hispanics and Asians than among whites ${ }^{(10)}$. Several studies have reported that presence of hunger or severity of food insecurity may influence the association between food insecurity and obesity ${ }^{(9)}$. Another study of low-income Latina women in six California counties reported a higher prevalence of overweight and obesity among those with food insecurity with hunger ${ }^{(12)}$. In a nationally representative sample of both sexes, individual (not household) food insecurity was associated with increased obesity risk among whites and Hispanics, but not blacks $^{(11)}$. In our study, FC was assessed as a binary exposure without a severity measurement. As a result, the food insecurity and obesity association might be obscured in populations with a high prevalence of severe food insecurity (e.g. food insecurity with hunger).

In contrast to these studies, our stratified analysis of obesity prevalence highlights the health burden of FC on whites, regardless of place of birth or sex, and certain subgroups of blacks, but found no effect of FC among Hispanics or Asians. In addition, our multivariable findings highlight higher risk of obesity among FC white New Yorkers. In the USA, the increasing prevalence of obesity has paralleled the increased energy density of foods consumed by blacks and whites ${ }^{(27)}$. Given the inverse relationship between energy density and food $\operatorname{cost}^{(8)}$, food-insecure whites and blacks may be particularly vulnerable to a low-cost, energy-dense diet conducive to obesity. Our findings suggest that white men - the only male New Yorkers to experience increased obesity with FC - may be particularly susceptible to this pattern. One possible explanation is the difference in levels of occupational physical activity among lower-income white males compared with other groups ${ }^{(28)}$, but data were not available in the present study to examine occupational physical activity and additional research is needed to explore their increased burden.

We also observed racial/ethnic differences among foreign-born New Yorkers in the association between FC and obesity: a higher prevalence of obesity was observed among FC than non-FC foreign-born whites and blacks, but not foreign-born Hispanics and Asians. The availability of affordable ethnic foods and large ethnic communities in NYC may slow the acculturation process for foreign-born adults, and may have an effect on their US-born counterparts as well. This would have a differential impact on the racial/ethnic groups. Among the $70 \%$ of NYC Asians and $39 \%$ of Hispanics who are foreign born ${ }^{(29)}$, lack of acculturation to the American diet may protect against obesity $^{(30,31)}$. Traditional Asian diets are characterized by high-fibre carbohydrates and low amounts of animal fat. Hispanic diets have less sugar, sugar-sweetened beverages and added fats than American diets, although more whole milk and cooking with animal fat ${ }^{(32,33)}$. However, lack of acculturation may not be protective for whites and blacks. Foreign-born white New Yorkers are largely from European countries where diets have high saturated fat content and low amounts of fruit and vegetables ${ }^{(34,35)}$. Foreign-born black New Yorkers are primarily from the West Indies ${ }^{(34)}$, where an association has been identified between obesity and lower socio-economic status ${ }^{(36)}$. Thus, foreign-born whites and blacks who are food insecure may rely on diets that have higher energy density than those of foreign-born Hispanics or Asians.

Our findings of higher obesity prevalence among black and white women suggest that they are important subgroups on which to focus efforts to alleviate food insecurity and associated health risks. Obesity prevalence may be higher among women specifically because women may be the first in their household to compromise their diet when resources are depleted or be more 
likely to consume energy-dense foods during periods of stress $^{(37)}$. In addition, women with families are more likely to experience food insecurity and be obese due to postpartum weight retention ${ }^{(38)}$. The burden of obesity in women may have additional important implications as women are often the main providers of health care and nutrition for their children ${ }^{(39)}$.

In addition to being more likely to consume low-cost, energy-dense foods, food-insecure individuals may seek monthly lump sums of public assistance, such as the Special Supplemental Nutrition Program for Women, Infants, and Children (WIC), National School Lunch and Breakfast Programs, FoodShare (Food Stamps) and Temporary Assistance for Needy Families. The cycle of assistance may lead to binge eating at the beginning of the month when individuals have the means to purchase food and fasting at the end of the month when resources are depleted ${ }^{(14,15)}$. This feast-famine cycle has been associated with a biological predisposition to both obesity and diabetes in observational studies and animal models ${ }^{(16,40,41)}$.

A report of a positive association between food insecurity and diabetes, independent of weight status, prompted us to explore this association. Seligman et al. observed that severe, not mild, food insecurity was associated with self-reported diabetes mellitus in a crosssectional survey representative of the US population that assessed food insecurity severity ${ }^{(18)}$. However, another study using the same food insecurity severity measure among low-income Ohio Appalachians found that food insecurity status was not associated with either selfreported or objective markers of diabetes status (random blood glucose and glycated $\mathrm{Hb}, \mathrm{HbA1c})^{(17)}$. While that study had the advantage of having data on food insecurity severity and objectively measured markers of diabetes, participants were selected to participate through a convenience sample and results were not adjusted for socioeconomic factors or obesity. Our population-based study of lower-income adult New Yorkers did not detect a direct positive association between FC and diabetes in either unadjusted or adjusted analyses independent of obesity and socio-economic characteristics. It is possible that this association between food insecurity and diabetes varies by food insecurity severity, which was not measured in our study. Despite our null findings regarding FC and diabetes, existing studies ${ }^{(9)}$ and our results point to an association between food insecurity and obesity in certain populations, and there is strong evidence linking obesity and diabetes. Thus, interventions to address obesityassociated risk of food insecurity - such as the promotion of nutrient-dense, lower-energy foods through subsidized income programmes - should, in turn, promote diabetes prevention in lower-income populations.

The present analyses have several strengths. The food insecurity and obesity association has not been previously examined at the local (city-wide) level, and this research contributes to sparse existing literature on the association between food insecurity and diabetes. In addition, poverty levels in NYC are substantially higher than the national average $^{(1)}$, and NYC has large non-white and immigrant populations, making it possible to explore relationships among low-income groups by both race/ethnicity and place of birth. Findings from the present study are relevant to urban environments with high poverty rates and can contribute to better understanding of the economic factors that may lead to obesity and diabetes.

Limitations of the study were primarily in measurement. Our analysis used self-reported height and weight to determine obesity status, similar to other studies. While the correlation between self-reported and measured BMI among adults is greater than $0 \cdot 90^{(42)}$, the few studies that used measured height and weight reported inconsistent associations $^{(17,37)}$. Diabetes status was also based on selfreport, which does not distinguish between type 1 and type 2 diabetes. In 2004, approximately 500000 New York adults had diagnosed diabetes, while another 200000 New Yorkers had diabetes but were unaware of it ${ }^{(6)}$. If a positive association between FC and diabetes exists independent of BMI, this misclassification may have attenuated our results.

The cross-sectional study design prevented the study of causal relationships between FC and obesity ${ }^{(43)}$. For example, it is possible that obesity may increase an individual's risk of becoming food insecure ${ }^{(42,44)}$. In addition, FC was assessed over the past $30 \mathrm{~d}$, a relatively short time frame, while obesity develops over a longer period of time. Misclassification of longer-term FC by using a question that measures shorter-term FC may have also attenuated our results. In addition, we did not have information on use of public assistance programmes among all lower-income New Yorkers and our study may have been underpowered to detect differences in odds of obesity by FC status among Asians. Results from lowerincome New Yorkers interviewed in the CHS may not be generalizable to rural individuals or those with higher incomes. In addition, the CHS excludes institutionalized individuals and those without a landline telephone.

\section{Conclusions}

We observed a higher prevalence of obesity among FC whites and certain subgroups of blacks, but no direct association between FC and diabetes. Our findings of a significant independent association among white New Yorkers provide additional insight into previous reports of a positive association among racial and ethnic minorities. In addition, the higher prevalence of obesity among FC white men attests to the importance of studying FC across genders. Future studies should aim to examine the effects of food insecurity in a prospective manner with sensitive measures of food insecurity and standardized measures of obesity. To reduce the possible effect of poor 
diet among those who are food insecure, programmes designed to alleviate food insecurity and poverty should promote the purchase and consumption of nutritious, lower-energy foods.

\section{Acknowledgements}

This study was supported by the New York City Department of Health and Mental Hygiene's Epi Scholars Program, funded by the Josiah Macy Jr. Foundation. The authors have no conflicts of interest to report. S.Y., E.C.O. and B.D.K. designed the research; E.C.O. and B.D.K. conducted the research; E.C.O. and B.D.K. provided essential materials; S.Y. and E.C.O. analysed the data; S.Y., E.C.O., K.H. and B.D.K. wrote the paper; S.Y. and E.C.O. have primary responsibility for the final content. All authors read and approved the final manuscript. The authors acknowledge the contributions made by the Epidemiology Services Survey Unit, directed by Donna Eisenhower, for collection of CHS data; the Data Unit, directed by Jennifer Norton, for CHS data management; Charles Wu for data checking; Timothy Frasca for preliminary data analysis; and participants of the CHS.

\section{References}

1. Van Wye G, Kerker BD, Matte T et al. (2008) Obesity and diabetes in New York City, 2002 and 2004. Prev Chronic Dis 5, A48.

2. New York City Department of Health and Mental Hygiene (2007) Epiquery: NYC Interactive Health Data System Community Health Survey 2007. http://nyc.gov/health/ epiquery (accessed January 2010).

3. James PT (2004) Obesity: the worldwide epidemic. Clin Dermatol 22, 276-280.

4. Banks J, Marmot M, Oldfield Z et al. (2006) Disease and disadvantage in the United States and in England. JAMA 295, 2037-2045.

5. Roberts M, Kerker B, Mostashari F et al. (2005) Obesity and health: risks and behaviors. NYC Vital Signs 4 , 1-4.

6. Kim M, Berger D \& Matte T (2006) Diabetes in New York City: Public Health Burden and Disparities. New York: New York City Department of Health and Mental Hygiene; available at http://www.nyc.gov/html/doh/downloads/ pdf/epi/diabetes_chart_book.pdf

7. Campbell CC (1991) Food insecurity: a nutritional outcome or a predictor variable? J Nutr 121, 408-415.

8. Drewnowski A \& Specter SE (2004) Poverty and obesity: the role of energy density and energy costs. Am J Clin Nutr 79, 6-16.

9. Dinour LM, Bergen D \& Yeh MC (2007) The food insecurity-obesity paradox: a review of the literature and the role food stamps may play. J Am Diet Assoc 107, 1952-1961.

10. Adams EJ, Grummer-Strawn L \& Chavez G (2003) Food insecurity is associated with increased risk of obesity in California women. J Nutr 133, 1070-1074.

11. Bhattacharya J, Currie J \& Haider S (2004) Poverty, food insecurity, and nutritional outcomes in children and adults. J Health Econ 23, 839-862.

12. Kaiser LL, Townsend MS, Melgar-Quinonez HR et al. (2004) Choice of instrument influences relations between food insecurity and obesity in Latino women. Am J Clin Nutr $\mathbf{8 0}$, 1372-1378.

13. Hu FB, Manson JE, Stampfer MJ et al. (2001) Diet, lifestyle, and the risk of type 2 diabetes mellitus in women. $N$ Engl J Med 345, 790-797.

14. Kempson KM, Palmer Keenan D, Sadani PS et al. (2002) Food management practices used by people with limited resources to maintain food sufficiency as reported by nutrition educators. J Am Diet Assoc 102, 1795-1799.

15. Wilde PE \& Ranney CK (2000) The monthly food stamp cycle: shopping frequency and food intake decisions in an endogenous switching regression framework. Am J Agric Econ 82, 200-213.

16. Kaufman D, Banerji MA, Shorman I et al. (2007) Early-life stress and the development of obesity and insulin resistance in juvenile bonnet macaques. Diabetes 56, 1382-1386.

17. Holben DH \& Pheley AM (2006) Diabetes risk and obesity in food-insecure households in rural Appalachian Ohio. Prev Chronic Dis 3, A82.

18. Seligman HK, Bindman AB, Vittinghoff E et al. (2007) Food insecurity is associated with diabetes mellitus: results from the National Health Examination and Nutrition Examination Survey (NHANES) 1999-2002. J Gen Intern Med 22, 1018-1023.

19. New York City Department of Health and Mental Hygiene (2004) Community Health Survey 2004 Methods. New York City: New York City Department of Health and Mental Hygiene; available at http://www.nyc.gov/html/doh/html/ survey/survey-2004.shtml

20. US Department of Health and Human Services (2010) The 2004 HHS Poverty Guidelines. http://aspe.hhs.gov/poverty/ 04poverty.shtml (accessed January 2010).

21. Centers for Disease Control and Prevention (1999) Behavioral Risk Factor Surveillance System Survey Questionnaire. Atlanta, GA: CDC.

22. Laraia BA, Siega-Riz AM \& Evenson KR (2004) Self-reported overweight and obesity are not associated with concern about enough food among adults in New York and Louisiana. Prev Med 38, 175-181.

23. VanEenwyk J (2003) Centers for Disease Control and Prevention. Self-reported concern about food security associated with obesity - Washington, 1995-1999. MMWR Morb Mortal Wkly Rep 52, 840-842.

24. National Heart, Lung, and Blood Institute \& National Institute of Diabetes and Digestive and Kidney Diseases (1998) Clinical Guidelines on the Identification, Evaluation, and Treatment of Overweight and Obesity in Adults: The Evidence Report. Bethesda, MD: NHLBI.

25. United States Census (2000) Summary File 3 (SF3). Washington, DC: US Census Bureau.

26. Webb AL, Schiff A, Currivan D et al. (2008) Food Stamp Program participation but not food insecurity is associated with higher adult BMI in Massachusetts residents living in low-income neighbourhoods. Public Health Nutr 11, 1248-1255.

27. Kant AK, Graubard BI \& Kumanyika SK (2007) Trends in black-white differentials in dietary intakes of US adults, 1971-2002. Am J Prev Med 32, 264-272.

28. Folsom AR, Cook TC, Sprafka JM et al. (1991) Differences in leisure-time physical activity levels between blacks and whites in population-based samples: the Minnesota Heart Survey. J Behav Med 14, 1-9.

29. US Census Bureau (2004) American Fact Finder. http:// factfinder.census.gov/servlet/DTTable?_bm $=y \&-$ context $=$ dt\&-ds_name $=$ ACS_2004_EST_G00_\&-mt_name $=$ ACS_2004_ EST_G2000_B06004B\&-mt_name=ACS_2004_EST_G2000_ B06004D\&-mt_name $=$ ACS_2004_EST_G2000_B06004I\&CONTEXT $=$ dt $\&$-tree_id $=304 \&$-all_geo_types $=$ N\&-geo_id $=$ 38500US56025600\&-search_results $=01000$ US $\&$-format $=\&$ lang $=$ en (accessed January 2010). 
30. Lv N \& Cason KL (2004) Dietary pattern change and acculturation of Chinese Americans in Pennsylvania. $J$ Am Diet Assoc 104, 771-778.

31. Guendelman S \& Abrams B (1995) Dietary intake among Mexican-American women: generational differences and a comparison with white non-Hispanic women. Am J Public Health 85, 20-25.

32. Drewnowski A \& Popkin BM (1997) The nutrition transition: new trends in the global diet. Nutr Rev $\mathbf{5 5}$, 31-43.

33. Ayala GX, Baquero B \& Klinger S (2008) A systematic review of the relationship between acculturation and diet among Latinos in the United States: implications for future research. J Am Diet Assoc 108, 1330-1344.

34. US Census Bureau (2003) Census 2000, Public Use Microdata Sample (PUMS). Washington, DC: US Census Bureau.

35. Kesteloot H, Sans S \& Kromhout D (2006) Dynamics of cardiovascular and all-cause mortality in Western and Eastern Europe between 1970 and 2000. Eur Heart J 27, 107-113.

36. Ichinohe M, Mita R, Saito K et al. (2005) The prevalence of obesity and its relationship with lifestyle factors in Jamaica. Toboku J Exp Med 207, 21-32.
37. Lyons AA, Park J \& Nelson CH (2008) Food insecurity and obesity: a comparison of self-reported and measured height and weight. Am J Public Health 98, 751-757.

38. Gore SA, Brown DM \& West DS (2003) The role of postpartum weight retention in obesity among women: a review of the evidence. Ann Behav Med 26, 149-159.

39. Tanumihardjo SA, Anderson C, Kaufer-Horwitz M et al. (2007) Poverty, obesity, and malnutrition: an international perspective recognizing the paradox. J Am Diet Assoc 107, 1966-1972.

40. Townsend MS, Peerson J, Love B et al. (2001) Food insecurity is positively related to overweight in women. $J$ Nutr 131, 1738-1745.

41. Leung CW \& Villamor E (2011) Is participation in food and income assistance programmes associated with obesity in California adults? Results from a state-wide survey. Public Health Nutr 14, 645-652.

42. McAdams MA, Van Dam RM \& Hu FB (2007) Comparison of self-reported and measured BMI as correlates of disease markers in US adults. Obesity (Silver Spring) 15, 188-196.

43. Jones SJ \& Frongillo EA (2007) Food insecurity and subsequent weight gain in women. Public Health Nutr 10, 145-151.

44. Olson CM \& Strawderman MS (2008) The relationship between food insecurity and obesity in rural childbearing women. J Rural Health 24, 60-66. 